\title{
Anatomical Study of Position of the Rib Head for Placing Anterior Vertebral Body Screws in a Chinese Population
}

\author{
Estudio Anatómico de la Posición de la Cabeza de la Costilla para Colocar \\ Tornillos en la Zona Anterior del Cuerpo Vertebral en una Población China
}

${ }^{*, * *}$ X. H. Li; *D. C. Xu; ${ }^{* *}$ Z. J. Li \& ${ }^{* *}$ X. Wang

LI, X. H.; XU, D. C.; LI, Z. J. \& WANG, X. Anatomical study of position of the rib head for placing anterior vertebral body screws in a Chinese population.Int. J. Morphol., 29(2):463-472, 2011.

SUMMARY: Instrumentation of anterior vertebral body screws has become an important approach for treatment of unstable fracture or curvature of the spine, but little attention has been paid to the starting point of placing the screws and variability of the rib head position. We analyzed the variability of rib head position in a Chinese population in terms of the spinal canal and vertebral body using computed tomography (CT). Images from transverse CT scan of the T4-T12 vertebral bodies of 30 normal individuals were 3D reconstructed, and analyzed for measurement of parameters, which included: 1) distance between the left (or right) anterior border of the rib head and the posterior (or anterior) margin of the vertebral body [L(R )ARHP(A)VB], 2) left (or right) transverse dimension [L(R)TD], 3) left (or right) posterior (or anterior) safe angle [L(R)P(A)SA], and 4) distance between the inferior border of the left (or right) rib head and the superior (or inferior) end-plate in the sagittal plane [IL(R)RHS(I)EP]. The ARHPVB, PSA, and IRHIEP gradually decrease, but ARHAVB, TD, ASA, and IRHSEP gradually increase from T4 to T12, indicating that the position of the rib head changes from a more anterior position to a more posterior position and from a more superior position to a more inferior position as the number of the vertebra increases. Our study has provided comprehensive reference guide for accurate and safe instrumentation of vertebral body screws in treating related spine diseases.

KEY WORDS: Anterior thoracic instrumentation; Rib head; Vertebral body; Screw position; Vertebral anatomy.

\section{INTRODUCTION}

Anterior single rod instrumentation has been broadly used for the treatment of unstable fracture of the spinal column and idiopathic scoliosis, and it has a better effect of relieving compression of the spinal cord and spinal nerves, correcting hypokyphosis, and preventing vertebral body fusion, compared to the traditional posterior instrumentation for fixation (Betz et al., 1999; Betz et al., 2001; Lowe et al., 2003; Sweet et al., 1999). However, some authors think that anterior screw placement is more technically demanding and more risky (Assaker et al., 2001; Kamimura et al., 2002). Following the increasing use of this technique, there have been multiple reports about injury of the thoracic aorta or nerves by the screw tip or guide wire, and loss of stability of the fixed segment of the spine caused by loosening or pullout of the screw in anterior open thoracic or thoracoscopic surgery (Lenke, 2003; Sucato,
2003). Some authors think that the ideal position to place the vertebral body screw is at the center of the lateral part of the vertebral body near the superior and inferior endplates, keeping equal distance to either anterior or posterior margin of the vertebral body (Lowe et al., 2003; Lowe et al., 2002; Zhang et al., 2004). Recently, it has been broadly proposed that the thoracic anterior vertebral body screw should be placed anterior to the rib head, which keeps the screw away from the spinal cord and has a better clamping force (Parent et al., 2002; Sucato). Anatomical study of the position of the rib head is obviously of particular importance for safe and accurate anterior instrumentation. Some anatomical landmarks of the rib head have been identified as critical reference points for accurate placement of the screw, but most of the data so far are from Western populations.

\footnotetext{
* Section of Clinical Anatomy, Department of Anatomy, Southern Medical University, Guangzhou510515, Guangdong Province, P. R. China.

** Department of Anatomy, Inner Mongolia Medical College, Hohhot010059, Inner Mongolia, P. R. China.
} 
In this study, we did 3D reconstruction and anatomical analysis of the CT scan images from normal individuals in a Chinese population for identification of parameters that define the position of the rib head, aiming to provide comprehensive reference guide for accurate and safe instrumentation of vertebral body screws for treatment of spine diseases, and fill the blank in this field in Eastern populations.

\section{MATERIAL AND METHOD}

Patient population. Forty-two patients who visited the outpatient or emergency department of our hospital with a chief complaint of non-spine disease were subjected to postero-anterior and lateral chest X-ray radiography to exclude scoliosis deformity or other abnormalities of the spine, and all radiographs were double-blind assessed by three experienced doctors to avoid bias. Twelve patients were excluded from the study because of the following spine abnormalities identified by radiography: spondyloarthropathies, isthmic spondylolysis, idiopathic scoliosis (Scoles et al., 1991; Basobas et al., 2003), compression fracture, Scheuermann'skyphosis (Scoles et al.), and missing vertebrae. The other 30 patients with a normal spine from T1 to L1, 14 males (47\%) and 16 females (53\%) aged 16-68 years with an average age of 32.3 years, were included in this study, and further subjected to thoracic CT scan. Ethical approval for this study was obtained from Human Research Ethics Committee, and informed consent was obtained from the patients involved in the study.

Methods. CT scan of the thoracic spine was conducted using a GE HiSpeed NX/I (General Electric Company, USA) scanner with a slice thickness of $1.5 \mathrm{~mm}$. Images were uploaded to Centricity DICOM Viewer 2.1 (General Electric Company, USA). All transverse images were acquired from planes that are parallel to the superior endplate of each individual vertebra by carefully adjusting inclination of the vertebrae. The serial image data in Dicom format were imported to a computer system, and measurement of the position of the rib head was then performed by using Mimics (Materialise's Interactive Medical Image Control System) (Version 11.02, System ID: A13B0916F3XC, Materialise, Leuven). Twenty eight or 30 slices of CT scan were obtained from the transverse plane for each vertebra, and the images showing the rib head were used for the measurement. All images were analyzed separately by 2 doctors, and the rib head position was assessed by using angular and linear measurement mode in Mimics. The mean of the measurements by the 2 doctors was taken.
Measurement of transverse images. The following parameters were analyzed from the transverse slices of the vertebral bodies from the 4th thoracic (T4) level to the 12th thoracic (T12) level: The distances between the left or right anterior border of the rib head and the posterior margin of the vertebral body [(L/R)ARHPVB] (Fig. 1); the distances between the left or right anterior border of the rib head and the anterior margin of the vertebral body [(L/R)ARHAVB] (Fig. 1); the transverse dimension (TD), which was measured from the left or right anterior border of the rib head to the lateral cortex of the vertebral body [(L/R)TD] (Fig. 1). At T11 and T12, "P2" was defined as the most anterior aspect of the spinal canal. "Line 1" was drawn through the point "P2" across the vertebral body on the coronal plane, and its length from the end of the lateral cortex on one side to the end of the lateral cortex on the other side was measured which was designated the transverse dimension of T11 or T12 (Fig. 2); (Left/right) Posterior Safe Angle (L/RPSA) (Fig. 3): "O" was the most anterior aspect of the rib head. "Line 1" was drawn through the most anterior aspect of the rib heads, parallel to the coronal plane. "P" was the most anterolateral aspect (concave side) of the spinal canal. "Line 3 " was drawn through "P", perpendicular to "line 1". "A"

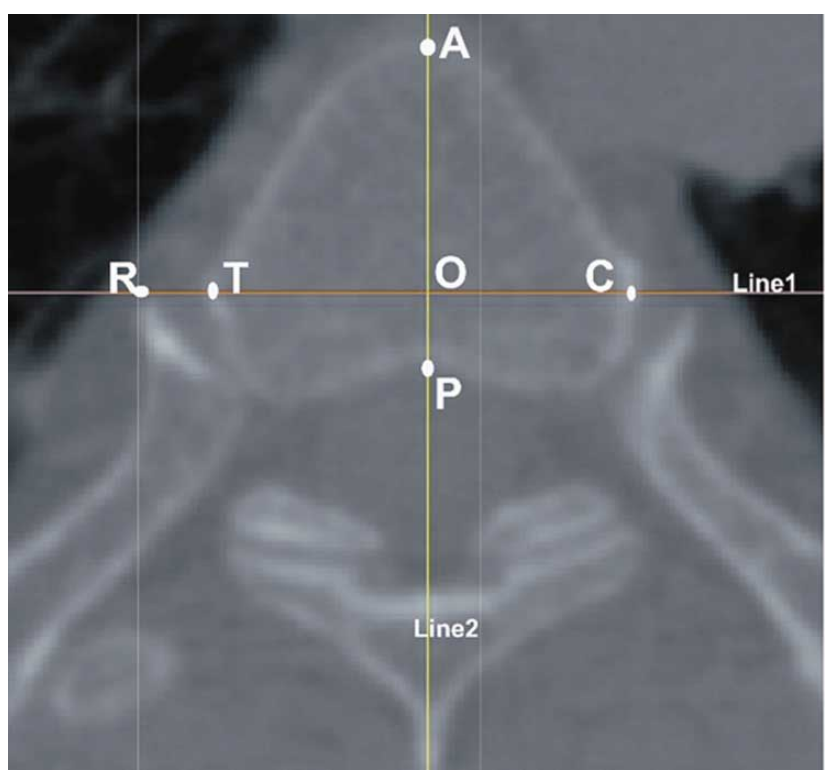

Fig. 1. The distance between anterior border of rib head and the posterior margin of the vertebral body (ARHPVB), the distance between anterior border of rib head and the anterior margin of the vertebral body (ARHAVB), and transverse dimension (TD)(Transverse CT): "Line 1" connects the most anterior aspect of the rib heads. "Line 2" is the line through the midsagittal plane of the vertebral body. "O" is the intersection between "lines 1 " and "lines 2 ". "A" is the point that line 2 intersects on the anterior margin of the vertebral body. "P" is the point that line 2 intersects the posterior margin of the vertebral body. "OA" is the ARHAVB. "OP" is ARHPVB, and "TC" is TD. 
was the most anterior aspect of the vertebrae body on "Line 3". (L/R) PSA is the angle between line "PO" and line 1, indicating the posterior safe angle for screw insertion; (left or right) anterior safe angle (L/RASA) (Fig. 3). The angle between "line AO" and "line 1" is designated as the anterior safe angle, which indicates the anterior safe angle for screw insertion (The position of Figs. 1-3).

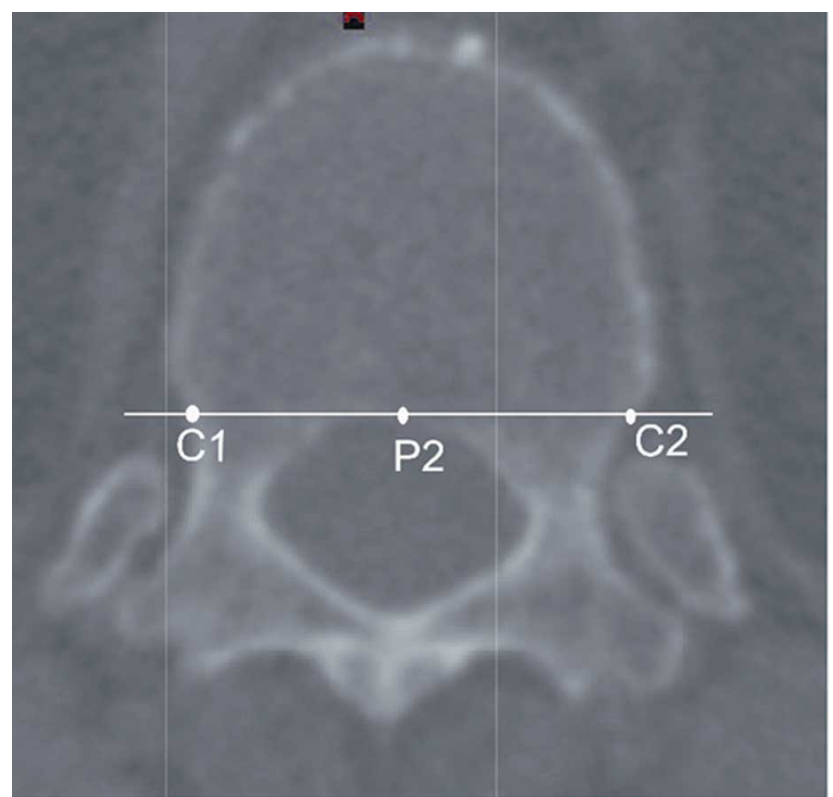

Fig. 2. The transverse dimension (TD) at T11 and T12 (Transverse $\mathrm{CT})$ : "P2" is posterior margin of the vertebral body, "C1C2" is TD at T11 and T12.

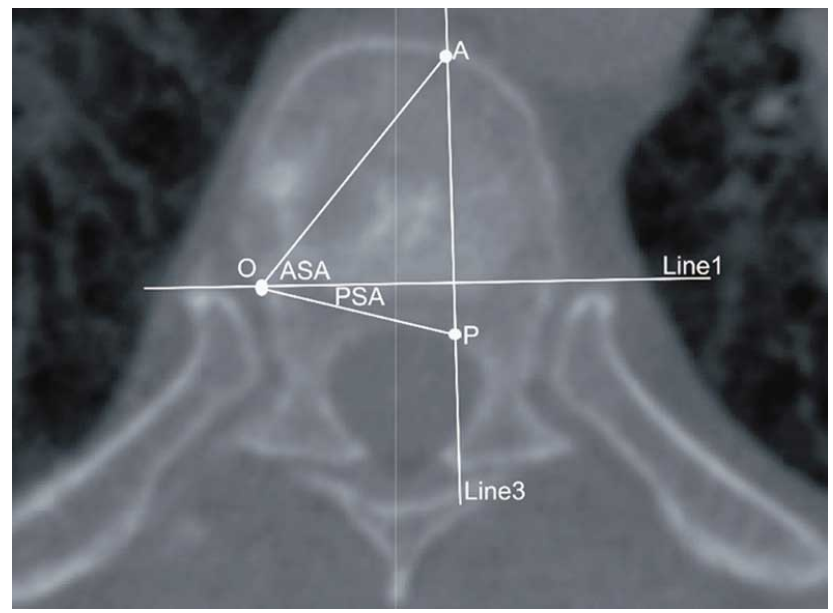

Fig. 3. The posterior safe angle (PSA) and anterior safe angle (ASA) (Transverse CT). "P" is the most antero-lateral aspect (concave side) of the spinal canal. "Line 3 " is a line through the $\mathrm{P}$, perpendicular to "line 1" and tangent to the lateral margin of the concave spinal canal. PSA is the angle subtended by "Line 1" and a line drawn from convex rib head to "P". "A" is the point that "line 3 " intersects the anterior margin of the vertebral body. ASA is the angle subtended by Line 1 and a line drawn from the convex rib head to "A".
3D rendering and measuring. Segmentation of transverse images: The CT images were first segmented using segmentation tools, such as threshold, region growing, boolean operation, and edit mask, to extract different tissues. The thoracic vertebrae and the rib head of interest were isolated by setting appropriate gray level thresholds to obtain the bone rim. Because some other structures, such as sternum, had a density similar to that of the thoracic vertebrae, further mask editing was necessary to remove these structures.

3D rendering: Once the T4-T12 vertebra and the rib head profiles were obtained, a surface rendering technique was used to reconstruct three-dimensional images, which were then analyzed for the following parameters: The distance between the most inferior aspect of (left or right) rib head and the superior end-plates in the sagittal plane [I(L/ R)RHSEP] (Fig. 4); the distance between the most inferior aspect of (left or right) rib head and the inferior end-plates in the sagittal plane [I(L/R)RHIEP] (Fig. 4).

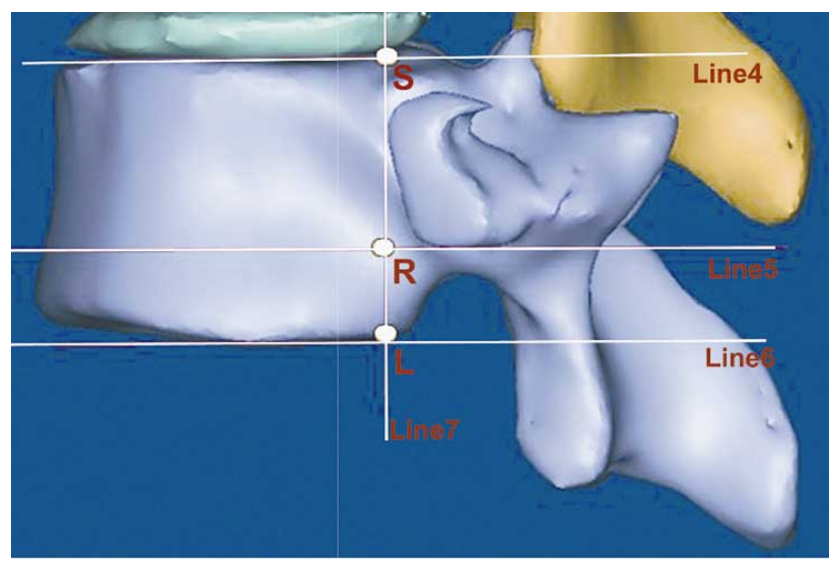

Fig. 4. The distance between the most inferior border of rib head and inferior-end-plate in the sagittal plane (IRHIEP) and the distance between the most inferior border of left rib head and superior-end-plate in the sagittal plane (IRHSEP). "Line 4" is a line parallel to superior end-plate, "Line 5" is drawn through the most inferior aspect of the rib head, parallel to "Line 4". "Line 6" is a line parallel to inferior end-plate. "Line 7" is drawn through the most anterior aspect of the rib head, perpendicular to Line 5. " $\mathrm{S}$ " is the point that "Line 4" intersects "line 7". "R" is the point that "Line 5" intersects "Line 7". "L" is the point that "Line 6" intersects "Line 7". "RS" is "IRHSEP". "RL" is "IRHIEP".

Data and statistical analysis. All measurements and the statistical analyses were performed using the Statistical Package for Social Sciences (SPSS, Chicago, IL, Version 13.0). All the data were presented as mean $\pm \mathrm{SD}$, and twoside difference analyses performed using the paired twotailed Student's t test. Probability values of less than 0.05 were considered to be statistically significant. 


\begin{tabular}{|c|c|}
\hline ABBREVIATION & UNABBREVIATION \\
\hline LARHPVB & The distance between left anterior border of rib head and the posterior margin of the vertebral body \\
\hline RARHPVB & The distance between right anterior border of rib head and the posterior margin of the vertebral body \\
\hline LARHAVB & The distance between left anterior border of rib head and the anterior margin of the vertebral body \\
\hline RARHAVB & The dis tance between right anterior border of rib head and the anterior margin of the vertebral body \\
\hline LTD & Left transverse dimension \\
\hline RTD & Right transverse dimension \\
\hline LPSA & Left posterior safe angle \\
\hline RPSA & Right po sterior safe angle \\
\hline ILRHIEP & The dist ance between the most inferior border of left rib head and inferior-end-plate in the sagittal plane \\
\hline IRRHIEP & The distance between the most inferior border of right rib head and inferior-end-plate in the sag ittal plane \\
\hline ILRHSEP & The distance between the most inferior border of left rib head and superior-end-plate in the sagittal plane \\
\hline IRRHSEP & The distance between the most inferior border of right rib head and superior-end-plate in the sagittal plane \\
\hline
\end{tabular}

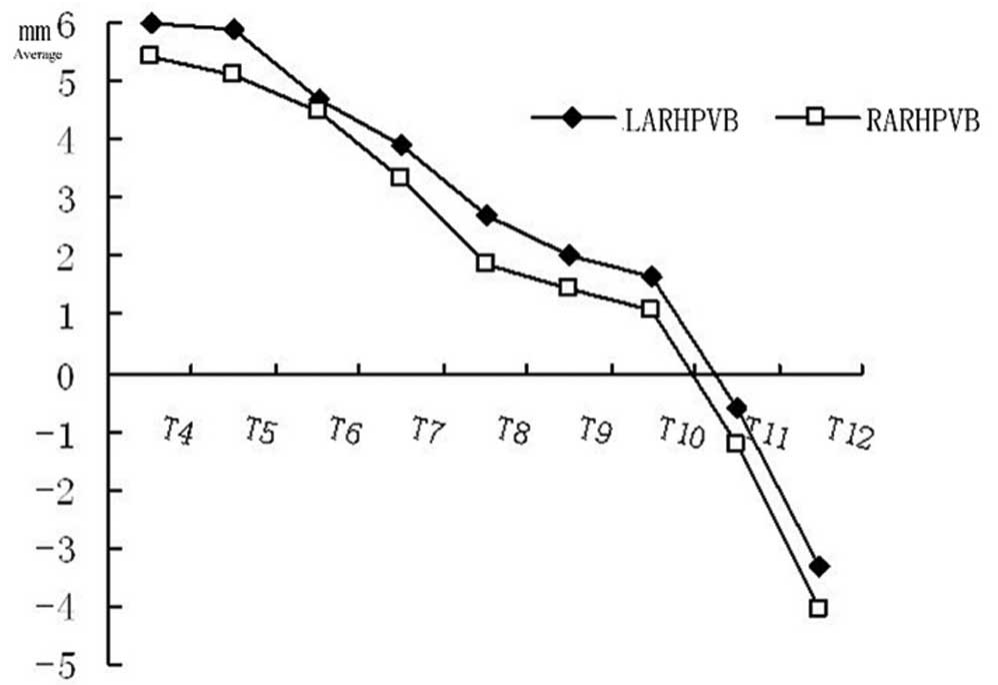

Fig. 5. Linear dimensions of the distance between left (right) anterior border of rib head and the posterior margin of the vertebral body (L/R) ARHPVB.

Table I. The Distance between left (Right) anterior border of rib head and the posterior margin of the vertebral body, $\mathrm{L}(\mathrm{R}) \mathrm{ARHPVB}(\mathrm{mm}, \mathrm{n}=30)$.

\begin{tabular}{cccccc}
\hline Vertebrae & \multicolumn{2}{c}{ LARHPVB } & \multicolumn{2}{c}{ RARHPVB } & P-value \\
\cline { 2 - 4 } & Average & SD & Average & SD & \\
\hline $\mathrm{T}_{4}$ & 5.98 & 1.68 & 5.43 & 1.75 & $0.903 \mathrm{a}$ \\
$\mathrm{T}_{5}$ & 5.89 & 1.36 & 5.09 & 1.67 & 0.012 \\
$\mathrm{~T}_{6}$ & 4.68 & 1.15 & 4.46 & 1.56 & $0.252 \mathrm{a}$ \\
$\mathrm{T}_{7}$ & 3.88 & 1.36 & 3.35 & 1.43 & 0.010 \\
$\mathrm{~T}_{8}$ & 2.70 & 0.83 & 1.88 & 1.27 & 0.001 \\
$\mathrm{~T}_{9}$ & 2.03 & 1.38 & 1.42 & 1.48 & 0.008 \\
$\mathrm{~T}_{10}$ & 1.66 & 1.64 & 1.06 & 1.57 & 0.001 \\
$\mathrm{~T}_{11}$ & -0.61 & 1.95 & -1.22 & 1.66 & 0.007 \\
$\mathrm{~T}_{12}$ & -3.31 & 2.38 & -4.04 & 2.80 & 0.013 \\
\hline
\end{tabular}

There is no significant difference between LARHPVB\&RARHPVB

\section{RESULTS AND DISCUSSION}

Images of the thoracic vertebrae and the rib head from a total of 30 subjects were used for analysis. The trend of the linear and angular parameters are shown in figures 5 and 10, and their numerical values are presented in Tables I and VII.

2-D measurements. The (L/R)ARHPVB (Table I, Fig. 5) showed a gradual decrease from the T4 level towards the T12 level. The values of T11 and T12 were negative. The smallest (L/ R)ARHPVB value was at the T12 level (left:$3.31 \mathrm{~mm}$; right:- $4.04 \mathrm{~mm}$ ) and the largest was at the T4 level (left:5.98mm; right:5.43mm). The measurements of ARHPVB also showed statistically significant difference between the left and right sides at all levels $(\mathrm{P}<0.05)$, except $\mathrm{T} 4$ and $\mathrm{T} 6(\mathrm{P}>0.05)$.

A gradual increase in (L/R)ARHAVB was found from T4 to T12 (Table II, Fig. 6), indicating that the rib head tend to get more posteriorly located with the increase of the number of the vertebrae. The smallest (L/ R)ARHAVB value was at T4 (left: $16.08 \mathrm{~mm}$; right: $16.91 \mathrm{~mm}$ ) and the largest was at the T12 level (left:28.90mm; right:29.51mm). The measurements of ARHAVB showed significant statistical difference between the left and right sides from $\mathrm{T} 5$ to $\mathrm{T} 9(\mathrm{P}<0.05)$, but no difference for the rest of the vertebrae $(\mathrm{P}>0.05)$. 


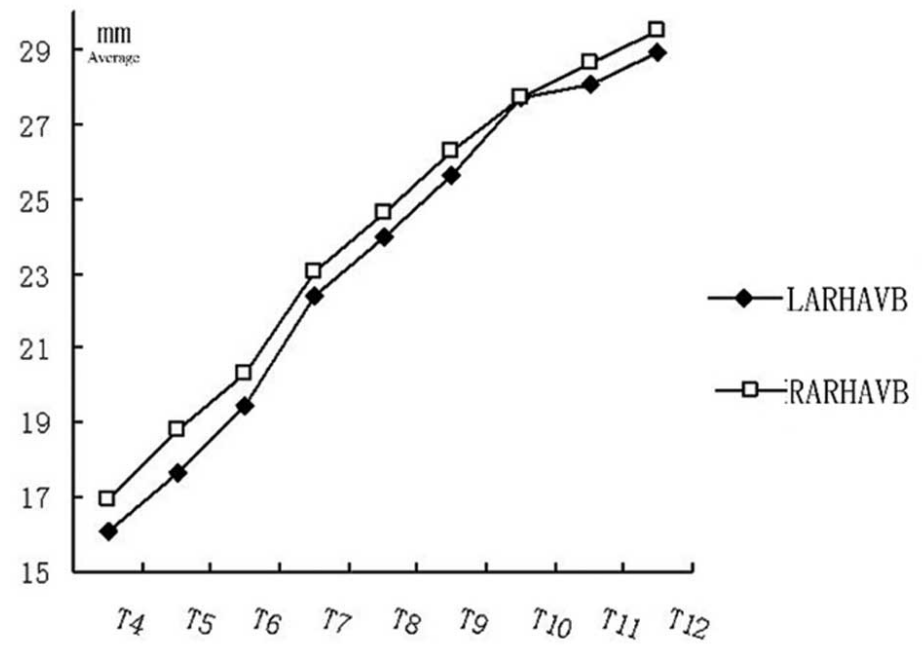

Fig. 6. Linear dimensions of the distance between left (right) anterior border of rib head and the anterior margin of the vertebral body, (L/R) A RHAVB.

Table II. The Distance between left (Right) anterior border of rib Head and the anterior margin of the vertebral body, (L/R) $\operatorname{ARHAVB}(\mathrm{mm}, \mathrm{n}=30)$.

\begin{tabular}{cccccc}
\hline \multirow{2}{*}{ Vertebrae } & \multicolumn{2}{c}{ LARHAVB } & \multicolumn{2}{c}{ RARHAVB } & \multirow{2}{*}{ P-value } \\
\cline { 2 - 4 } & Average & SD & Average & SD & \\
\hline $\mathrm{T}_{4}$ & 16.08 & 2.53 & 16.91 & 2.49 & 0.060 \\
$\mathrm{~T}_{5}$ & 17.69 & 2.42 & 18.81 & 2.67 & $0.015 \mathrm{~b}$ \\
$\mathrm{~T}_{6}$ & 19.43 & 2.08 & 20.28 & 2.21 & $0.000 \mathrm{~b}$ \\
$\mathrm{~T}_{7}$ & 22.41 & 2.17 & 23.04 & 2.43 & $0.027 \mathrm{~b}$ \\
$\mathrm{~T}_{8}$ & 23.94 & 2.17 & 24.63 & 2.58 & $0.008 \mathrm{~b}$ \\
$\mathrm{~T}_{9}$ & 25.65 & 2.48 & 26.26 & 2.37 & $0.018 \mathrm{~b}$ \\
$\mathrm{~T}_{10}$ & 27.67 & 3.53 & 27.67 & 2.73 & 0.987 \\
$\mathrm{~T}_{11}$ & 28.08 & 2.47 & 28.62 & 2.47 & 0.119 \\
$\mathrm{~T}_{12}$ & 28.90 & 2.57 & 29.51 & 2.31 & 0.057 \\
\hline
\end{tabular}

${ }^{\mathrm{b}}$ There is a significant difference between LARHAVB \& RARHAVB.

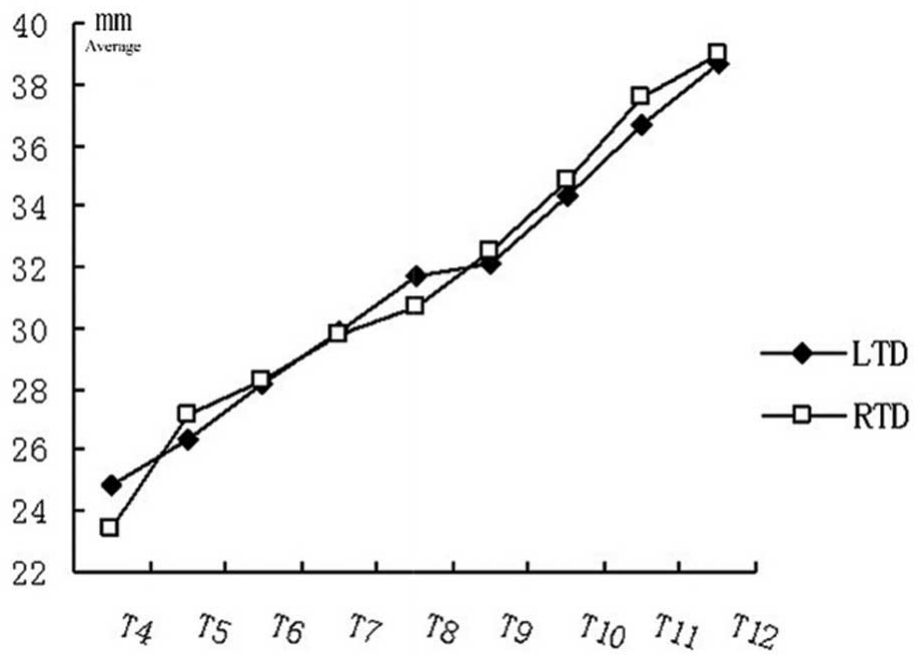

Fig. 7. Linear dimensions of Left (right) transverse dimension, (L/R) TD.
The transverse dimension (TD) (Table III, Fig. 7) showed a gradual increase from T4 to the T12. The smallest TD was at the T4 level (left: $24.88 \mathrm{~mm}$; right: $23.43 \mathrm{~mm}$ ) and the largest at the T12 level (left: $38.70 \mathrm{~mm}$; right: $39.03 \mathrm{~mm})$. The measurements showed no significant difference between the left and right sides $(\mathrm{P}>0.05)$, except for $\mathrm{T} 8(\mathrm{P}<0.05)$.

The PSA was gradually decreased from T4 to T12. The smallest PSA was at the T12 level (left: $-8.70^{\circ}$; right: $-9.57^{\circ}$ ) and the largest was at the T4 level (left: $22.06^{\circ}$; right: $20.42^{\circ}$ ). The measurements showed no significant difference between the left and right sides ( $\mathrm{P}>0.05)$, except for T5, T7, and T8 $(\mathrm{P}<0.05)$ (Table IV; Fig. 8).

The ASA was gradually increased from T4 to T8, stayed about the same from T8 to $\mathrm{T} 10$, but was decreased from $\mathrm{T} 11$ to $\mathrm{T} 12$. The smallest ASA was at the T4 level (left: 44.01 ${ }^{\circ}$; right: $44.04^{\circ}$ ) and the largest at the T9 level (left: $55.78^{\circ}$; right: $53.52^{\circ}$ ). The measurements showed no significant difference between the left and right sides ( $\mathrm{P}>0.05)$, except for T4, T5, and T7 ( $\mathrm{P}<0.05)$ (Table V; Fig. 9).

3-D measurements. A gradual increase was found in the I(L/R)RHSEP from T4 to T12. The smallest I (L/R)RHSEP was at the T4 level (left: $5.65 \mathrm{~mm}$; right: $5.76 \mathrm{~mm}$ ) and the largest was a the T12 level (left:14.36mm; right: $14.06 \mathrm{~mm})$. The measurements showed no significant difference between the left and right sides ( $\mathrm{P}>0.05$ ) (Table VI; Fig. 10).

The I(L/R)RHIEP seemed to have a gradual decrease from T4 to T12, but it stayed about the same from T5 to T12 (Table VII; Fig. 10). The smallest I(L/R)RHIEP was at the T11 level (left: $9.98 \mathrm{~mm}$; right: $10.22 \mathrm{~mm}$ ) and the largest was at the T4 level (left: $12.33 \mathrm{~mm}$; right: $11.52 \mathrm{~mm})$. The measurements showed no significant difference between the left and right sides (P>0.05), except for T7 and T9 $(\mathrm{P}<0.05)$ (The position of figure 5-10 and Table I-VII).

Anterior stabilization of thoracic vertebrae after trauma or neoplasm-related instability is an important component in surgical management. Anterior spinal 


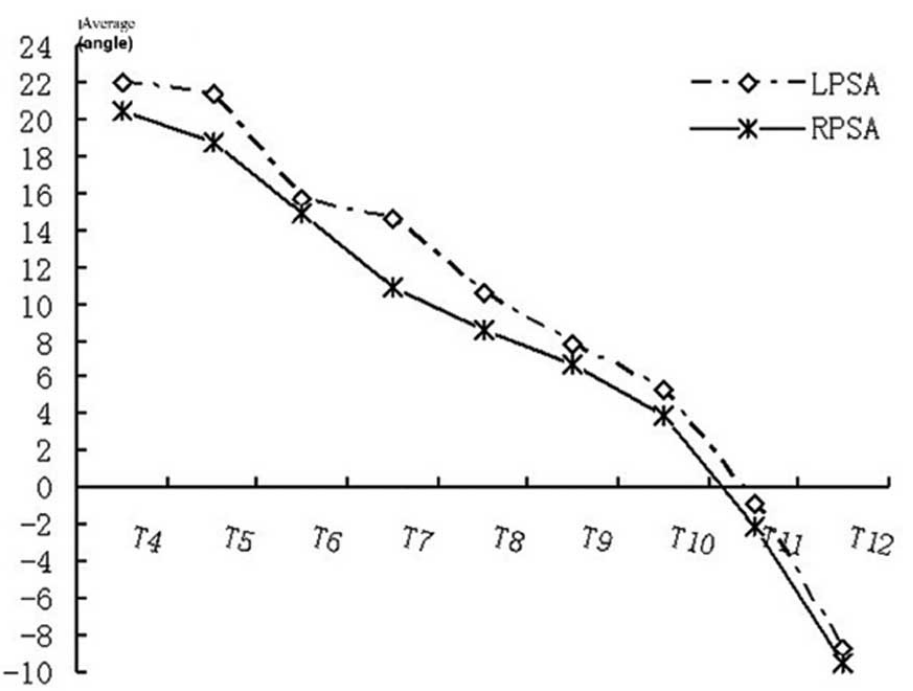

Fig. 8. Angular dimensions of left (right) posterior safe angle (L/R)PSA.

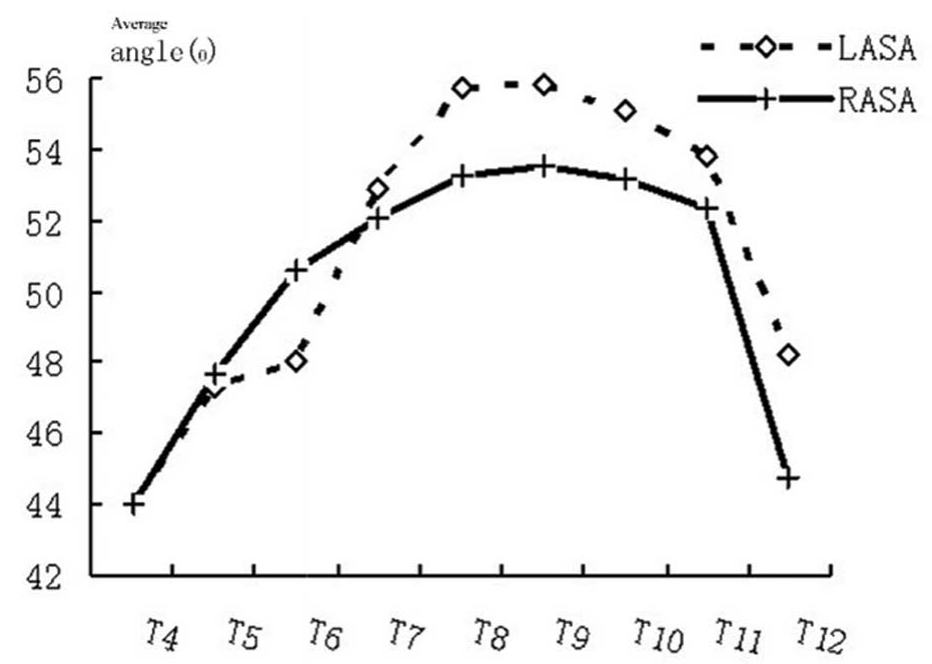

Fig. 9. Angular dimensions of left (right) anterior safe angle (L/R)ASA.

Table III. Left(Right) transverse dimension, (L/R)TD(mm,n=30)

\begin{tabular}{cccccc}
\hline Vertebrae & \multicolumn{2}{c}{ LTD } & \multicolumn{2}{c}{ RTD } & \multirow{2}{*}{ P-value } \\
\cline { 2 - 4 } & Average & SD & Average & SD & \\
\hline $\mathrm{T}_{4}$ & 24.88 & 2.64 & 23.43 & 2.67 & 0.231 \\
$\mathrm{~T}_{5}$ & 26.35 & 2.67 & 27.15 & 2.54 & 0.246 \\
$\mathrm{~T}_{6}$ & 28.18 & 2.54 & 28.32 & 2.50 & 0.723 \\
$\mathrm{~T}_{7}$ & 29.90 & 2.39 & 29.76 & 2.34 & 0.778 \\
$\mathrm{~T}_{8}$ & 31.72 & 2.57 & 30.67 & 2.91 & $0.002 \mathrm{~b}$ \\
$\mathrm{~T}_{9}$ & 32.10 & 3.06 & 32.51 & 3.10 & 0.503 \\
$\mathrm{~T}_{10}$ & 34.37 & 2.27 & 34.82 & 3.07 & 0.358 \\
$\mathrm{~T}_{11}$ & 36.71 & 2.30 & 37.59 & 3.24 & 0.059 \\
$\mathrm{~T}_{12}$ & 38.70 & 3.16 & 39.03 & 3.63 & 0.604 \\
\hline
\end{tabular}

${ }^{\mathrm{b}}$ There is a significant difference between LTD and RTD. instrumentation reduces fracturedislocation and helps to maintain stability and alignment of the thoracic vertebrae, thereby facilitating neurological recovery. It can also prevent late neurological sequelae and disabling mechanical pain due to post traumatic kyphosis. Compared with the posterior approach, the anterior approach has been reported to be superior for decompression when the spinal cord is compressed by fractured bone fragment or tumor. It has also been reported to have a better correction of spinal deformities with less fused segments in both idiopathic and neuromuscular deformities (Zhang \& Sucato, 2006). During surgical stabilization and instrumentation, it is critical to avoid injury of neural structures. Accurate and safe pathway of the anterior vertebrae body is important and requires precision and accuracy. Understanding of the precise anatomy of the vertebrae and neural structures is fundamentally important for accurate and safe access from the anterior vertebra body.

The ideal starting point for screw insertion has previously been considered to be just anterior to the head of the rib at each level (Mohamad et al., 2006). However, the position of the rib head is varied in the thoracic spine, so the actual starting position of the screw insertion should be dependent on the level of the thoracic vertebrae in which the screws are placed. Zhang et al. found that there was a decline in (L/R)ARHPVB from T3 to T12 in a porcine model, and they also analyzed the position of the rib head relative to the spinal canal and vertebral body in normal individuals and patients with right thoracic AIS in a Western population using magnetic resonance imaging (MRI) (Mohamad et al.). They indicated that the screws in the cephalic thoracic spine were mostly placed anteriorly, while the screws in the caudal thoracic spine were more commonly placed posteriorly. There has almost been no report about precise, quantitative measurements to assess the position of the rib head, especially in the Chinese population. 
Table IV. Left (Right) posterior safe angle, (L/R)PSA $\left(^{\circ}, \mathrm{n}=30\right)$.

\begin{tabular}{|c|c|c|c|c|c|}
\hline \multirow{2}{*}{ Vertebrae } & \multicolumn{2}{|c|}{ LPSA } & \multicolumn{2}{|c|}{ RPSA } & \multirow{2}{*}{$P$-value } \\
\hline & Average & SD & Average & SD & \\
\hline $\mathrm{T}_{4}$ & 22.06 & 5.74 & 20.42 & 4.04 & 0.192 \\
\hline $\mathrm{T}_{5}$ & 21.45 & 6.18 & 18.71 & 4.78 & $0.022 \mathrm{~b}$ \\
\hline $\mathrm{T}_{6}$ & 15.64 & 4.65 & 14.85 & 5.14 & 0.364 \\
\hline $\mathrm{T}_{7}$ & 14.52 & 3.98 & 10.91 & 3.50 & $0.000 \mathrm{~b}$ \\
\hline $\mathrm{T}_{8}$ & 10.50 & 3.73 & 8.49 & 2.87 & $0.016^{\mathrm{b}}$ \\
\hline $\mathrm{T}_{9}$ & 7.78 & 3.52 & 6.69 & 3.52 & 0.134 \\
\hline $\mathrm{T}_{10}$ & 5.24 & 5.06 & 3.90 & 3.74 & 0.160 \\
\hline $\mathrm{T}_{11}$ & -0.94 & 5.96 & -2.14 & 5.40 & 0.256 \\
\hline $\mathrm{T}_{12}$ & -8.70 & 4.15 & -9.57 & 4.21 & 0.410 \\
\hline
\end{tabular}

${ }^{b}$ There is a significant difference between LPSA \& RPSA.

Table V. Left (Right) anterior safe angle, (L/R)ASA $\left({ }^{\circ}, \mathrm{n}=30\right)$.

\begin{tabular}{cccccc}
\hline Vertebrae & \multicolumn{2}{c}{ LASA } & \multicolumn{2}{c}{ RASA } & P-value \\
\cline { 2 - 5 } & Average & SD & Average & SD & \\
\hline $\mathrm{T}_{4}$ & 44.01 & 5.15 & 44.04 & 6.24 & 0.975 \\
$\mathrm{~T}_{5}$ & 47.35 & 5.52 & 47.64 & 5.55 & 0.645 \\
$\mathrm{~T}_{6}$ & 48.00 & 6.13 & 50.60 & 6.24 & $0.037^{\mathrm{b}}$ \\
$\mathrm{T}_{7}$ & 52.88 & 4.89 & 52.04 & 4.97 & 0.373 \\
$\mathrm{~T}_{8}$ & 55.73 & 2.87 & 53.29 & 2.84 & $0.000^{\mathrm{b}}$ \\
$\mathrm{T}_{9}$ & 55.78 & 3.78 & 53.52 & 3.22 & $0.003^{\mathrm{b}}$ \\
$\mathrm{T}_{10}$ & 55.06 & 4.06 & 53.19 & 4.26 & $0.009^{\mathrm{b}}$ \\
$\mathrm{T}_{11}$ & 53.83 & 4.99 & 52.31 & 4.48 & $0.020^{\mathrm{b}}$ \\
$\mathrm{T}_{12}$ & 48.18 & 8.45 & 44.73 & 9.23 & $0.020^{\mathrm{b}}$ \\
\hline
\end{tabular}

bThere is a significant difference between LASA \& RASA.

Table VI. The distance between the most inferior border of left (Right) rib head and superior-end-plate in the sagittal plane, I (L/R) RHSEP (mm,n=30).

\begin{tabular}{cccccc}
\hline \multirow{2}{*}{ Vertebrae } & \multicolumn{2}{c}{ ILRHSEP } & \multicolumn{2}{c}{ IRRHSEP } & P-value \\
\cline { 2 - 5 } & Average & SD & Average & SD & \\
\hline $\mathrm{T}_{4}$ & 5.65 & 1.36 & 5.76 & 1.73 & 0.682 \\
$\mathrm{~T}_{5}$ & 6.26 & 1.45 & 6.05 & 1.51 & 0.314 \\
$\mathrm{~T}_{6}$ & 6.65 & 1.03 & 6.94 & 1.22 & 0.194 \\
$\mathrm{~T}_{7}$ & 7.36 & 1.04 & 7.09 & 1.19 & 0.269 \\
$\mathrm{~T}_{8}$ & 8.15 & 1.02 & 7.94 & 1.34 & 0.310 \\
$\mathrm{~T}_{9}$ & 9.15 & 1.13 & 8.77 & 1.46 & 0.066 \\
$\mathrm{~T}_{10}$ & 10.41 & 2.02 & 10.50 & 2.05 & 0.661 \\
$\mathrm{~T}_{11}$ & 12.06 & 2.07 & 11.77 & 2.12 & 0.259 \\
$\mathrm{~T}_{12}$ & 14.36 & 2.15 & 14.06 & 1.68 & 0.310 \\
\hline
\end{tabular}

This study has demonstrated that the position of the rib head changes from a more anterior position in the cephalic thoracic spine to a more posterior position in the caudal thoracic spine in a Chinese population based on measurement of the (L/R)ARHPVB. The average value of (L/R)ARHPVB on the left side at T4 was $5.98 \mathrm{~mm}$, and that on the right was $5.43-\mathrm{mm}$; The average value of (L/R)ARHPVB on the left side at $\mathrm{T} 12$ was $-0.31 \mathrm{~mm}$, and that on the right side was (-4.04)-mm. The average value of (L/ R)ARHAVB on the left side at T4 was $16.08 \mathrm{~mm}$, and that on the right side was $16.91 \mathrm{~mm}$; The average value of (L/R)ARHAVB on the left side at T12 was $28.90 \mathrm{~mm}$, and that on the right side was $29.51 \mathrm{~mm}$, which is similar to that in the Western population reported by Zhang \& Sucato. We have further found that the anterior aspect of rib head at $\mathrm{T} 11$ and $\mathrm{T} 12$ is posterior to the posterior border of the vertebral body (The values of (L/ R)ARHPVB were all negative).

We are the first to point out how the screws should be positioned in different segment of the T4-T12 thoracic spine (either anterior or posterior to the anterior rib head). The screw sizes of the standard stainless steel Moss-Miami (DePuy Spine, Inc., Raynham, MA) for anterior instrumentation were 5, 6, and 7-mm in diameter (Sucato et al., 2004). Taken the $6 \mathrm{~mm}$ diameter screw for example, the screws should be placed posterior to the anterior rib head in the T4-T7 segment if the anterior aspect of rib head is used as the starting point for screw insertion. The screw starting point at T4 on the left side was located $2.98-\mathrm{mm}$ posterior to the anterior rib head, and that on the right side was $2.43 \mathrm{~mm}$; the screw starting point at $\mathrm{T} 7$ on the left was $0.88 \mathrm{~mm}$, and that on the right side was $0.35 \mathrm{~mm}$. However, screws should be placed anterior to the anterior rib head in the T8-T12 segment. The screw starting point at T8 on the left side was located $0.30 \mathrm{~mm}$ anterior to the anterior rib head, and that on the right side was $1.12 \mathrm{~mm}$; the screw starting point at T12 on the left side was $6.31 \mathrm{~mm}$, and that on the right side was $7.04 \mathrm{~mm}$. Comparison of ARHPVB and ARHAVB between the left and right sides revealed a difference in those parameters at most T4-T12 levels, which should be taken into consideration in designing the surgery. However, further study with a larger sample size is needed to more comprehensively address this question. 
Table VII. The Distance between the most inferior border of left (Right) rib head and inferior-end-plate in the sagittal plane, I (L/R) RHIEP $(\mathrm{mm}, \mathrm{n}=30)$.

\begin{tabular}{cccccc}
\hline \multirow{2}{*}{ Vertebrae } & \multicolumn{2}{c}{ ILRHIEP } & \multicolumn{2}{c}{ IRRHIEP } & \multirow{2}{*}{ P-value } \\
\cline { 2 - 4 } & Average & $\mathrm{SD}$ & Average & $\mathrm{SD}$ & \\
\hline $\mathrm{T}_{4}$ & 12.33 & 2.14 & 11.52 & 2.19 & 0.053 \\
$\mathrm{~T}_{5}$ & 11.78 & 1.09 & 11.76 & 1.28 & 0.934 \\
$\mathrm{~T}_{6}$ & 11.69 & 1.30 & 11.87 & 1.26 & 0.383 \\
$\mathrm{~T}_{7}$ & 10.83 & 1.39 & 11.95 & 1.26 & $0.000 \mathrm{~b}$ \\
$\mathrm{~T}_{8}$ & 11.75 & 1.18 & 12.07 & 1.16 & 0.136 \\
$\mathrm{~T}_{9}$ & 11.59 & 1.24 & 12.22 & 1.34 & $0.022 \mathrm{~b}$ \\
$\mathrm{~T}_{10}$ & 10.22 & 2.76 & 10.74 & 1.87 & 0.189 \\
$\mathrm{~T}_{11}$ & 9.98 & 2.45 & 10.22 & 2.58 & 0.231 \\
$\mathrm{~T}_{12}$ & 10.83 & 2.80 & 10.90 & 2.89 & 0.619 \\
\hline
\end{tabular}

${ }^{b}$ There was a significant difference between ILRHIEP\& IRRHIEP.

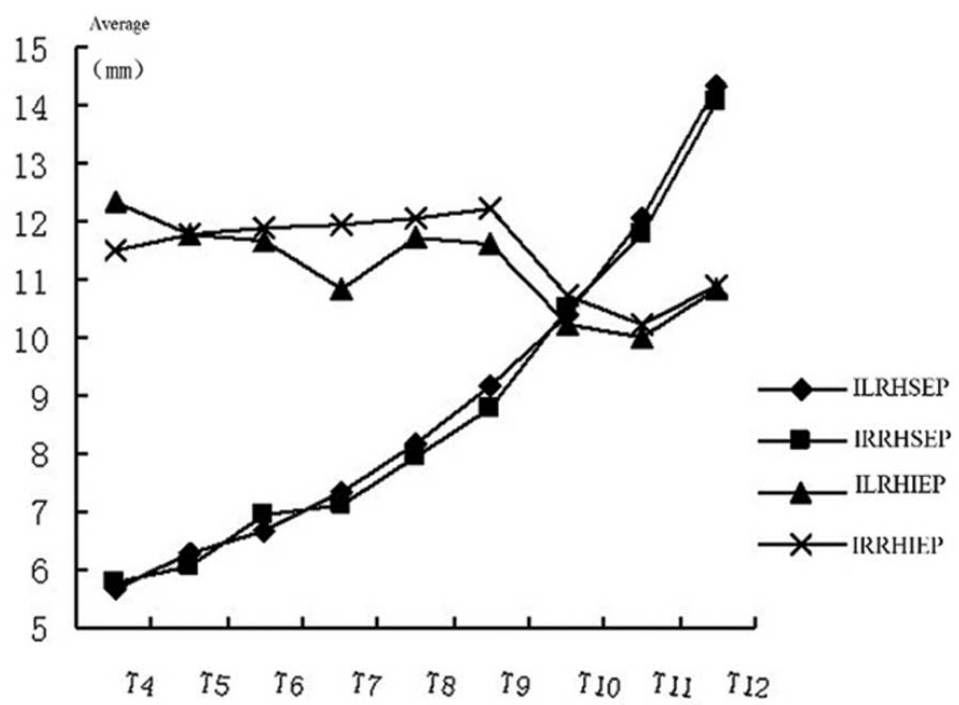

Fig. 10. Linear dimensions of the distance between the most inferior border of left rib head and inferior-end-plate in the sagittal plane, I (L/R) RHIEP and the distance between the most inferior border of left rib head and superiorend-plate in the sagittal plane I (L/R) RHSEP.

The transverse dimension (TD) is a crucial parameter for selecting an appropriate screw size. Inappropriate size or length of the screw may cause potential injury to the spinal cord and even the aorta. In our study, we have found that the transverse dimension gradually increases from T4 towards T12, which is consistent with previous studies (Zhang \& Sucato). This study has revealed no difference between the left and right sides in TD, except for T8. The surgeons could select the screw size for both sides based on the TD.

Besides the correct starting point, accurate angulation of the screw into the vertebral body was also a very important parameter for the screw insertion in order to achieve effective fixation and to reduce the risks of screw pullout, vertebral fracture, and spinal cord and aorta injuries. This study has demonstrated that the posterior safe insertion angle (PSA) is the largest at T4, and it decreases gradually from $\mathrm{T} 4\left(22.06^{\circ}\right.$ on the left and $20.42^{\circ}$ on the right) to $\mathrm{T} 12\left(-8.70^{\circ}\right.$ on the left and $-9.57^{\circ}$ on the right). This observation is consistent with previous studies (Zhang et al.). The trend of PSA revealed in this study is similar to that from a previous study, but the values of PSA by CT in our study are slightly smaller than those by MRI in that study (Zhang \& Sucato). The anterior safe angle (ASA) has been shown in our study to be larger in the T7-T11 segment than that of other segments of the T4-T12 levels, which is different from the finding by Zhang $\&$ Sucato that the ASA of the most cephalic thoracic vertebrae (T4, T5, and T6 in the normal individuals, and $\mathrm{T} 4$ and $\mathrm{T} 5$ in patients with scoliosis) are significantly smaller than that of all other thoracic vertebrae (Zhang \& Sucato). Some researchers have suggested that this difference may probably be due to different methods used for the measurement (Kamimura et al.), but we think that this may possibly be related to genetic endowment and environmental factors. Thorough anatomical studies are needed to further clarify this disparity, we have reconstructed three-dimensional images from the 2D images of T4-T12, and measured the linear dimensions of I (L/R)RHSEP and I (R/ L)RHIEP. The I(L/R)RHSEP has shown a gradual increase from T4 level to T12 level, while I(L/ R)RHIEP has no such tendency. The variable range of $\mathrm{I}(\mathrm{L} / \mathrm{R}) \mathrm{RHIEP}$ is small $(9.98-12.33 \mathrm{~mm})$. There is no difference between the left and right sides in both IRHSEP and IRHIEP across T4-T12 levels, except for T7 and T9 in IRHIEP. This study has also revealed that the position of the rib head not only changes from a more anterior position in the cephalic thoracic spine to a more posterior position in the caudal part, but also changes from a more superior position in the cephalic thoracic spine to a more inferior position in the caudal part, which has raised a critical point doctors have to take into consideration in designing the surgery.

We have analyzed in this study the anatomical parameters of the T4-T12 thoracic vertebrae in a Chinese population that are critical in determining the position and direction of screw instrumentation in the thoracic spine, which can greatly improve the accuracy of the surgery, increase the stability of the spine and reduce the risk of injuries to the surrounding tissues. 
LI, X. H.; XU, D. C.; LI, Z. J. \& WANG, X. Estudio anatómico de la posición de la cabeza de la costilla para colocar tornillos en la zona anterior del cuerpo vertebral en una población china. Int. J. Morphol., 29(2):463-472, 2011.

RESUMEN: La instrumentación del cuerpo anterior vertebral con tornillos ha sido una vía importante para el tratamiento de las fracturas inestables y curvaturas de la columna, pero se ha prestado poca atención a la zona de colocación de los tornillos y la variabilidad de la posición de la cabeza costal. Se analizó la variabilidad de la posición de la cabeza de la costilla en una población de China en relación al canal vertebral y cuerpo vertebral mediante tomografía computarizada (TC). Imágenes de cortes transversales de TC correspondientes a los cuerpos vertebrales T4-T12 de 30 individuos normales fueron reconstruidos tridimensionalmente, y se analizó la medida de algunos parámetros: 1) la distancia entre el margen anterior izquierdo (o derecho) de la cabeza de la costilla y el margen posterior (o anterior) del cuerpo vertebral [L(R)ARHP(A)VB], 2) Dimensión transversa izquierda (o derecha) [L(R)TD], 3) ángulo de seguridad izquierdo (o derecho) posterior (o anterior) $[\mathrm{L}(\mathrm{R}) \mathrm{P}(\mathrm{A}) \mathrm{SA}]$, y 4) la distancia entre el margen inferior de la cabeza de la costilla izquierda (o derecha) y la placa terminal superior (o inferior) en el plano sagital [IL(R)RHS(I)EP]. El ARHPVB, PSA, y IRHIEP disminuyeron gradualmente, pero ARHAVB, TD, ASA, y IRHSEP aumentaron gradualmente de T4 a T12, lo que indica que la posición de la cabeza de la costilla cambia desde una posición más anterior a una posición más posterior y de una posición más superior a una posición más inferior a medida que aumenta el número de vértebras. Nuestro estudio ha proporcionado completa guía de referencia para la instrumentación precisa y segura de tornillos en el cuerpo vertebral para el tratamiento de enfermedades relacionadas con la columna vertebral.

PALABRAS CLAVE: Instrumentación torácica anterior, Cabeza de la costilla; Cuerpo vertebral; Posición del tornillo; Anatomía vertebral.

\section{REFERENCES}

Assaker, R.; Reyns, N.; Pertruzon, B. \& Lejeune, J. P. Imageguided endoscopic spine surgery: Part II: clinical applications. Spine, 26(15):1711-8, 2001.

Basobas, L.; Mardjetko, S.; Hammerberg, K. \& Lubicky, J. Selective anterior fusion and instrumentation for the treatment of neuromuscular scoliosis. Spine, 28(20):S245-8, 2003.

Betz, R. R.; Harms, J.; Clements, D. H. 3rd.; Lenke, L. G.; Lowe, T. G.; Shufflebarger, H. L.; Jeszenszky, D. \& Beele, B. Comparison of anterior and posterior instrumentation for correction of adolescent thoracic idiopathic scoliosis. Spine, 24(3):225-39, 1999.

Betz, R. R. \& Shufflebarger, H. Anterior versus posterior instrumentation for the correction of thoracic idiopathic scoliosis. Spine, 26(9):1095-100, 2001.

Kamimura, M.; Kinoshita, T.; Itoh, H.; Yuzawa, Y.; Takahashi, J.; Hirabayashi, H. \& Nakamura, I. Preoperative CT examination for accurate and safe anterior spinal instrumentation surgery with endoscopic approach. J. Spinal Disord. Tech., 15(1):47-52, 2002.

Lenke, L. G. Anterior endoscopic discectomy and fusion for adolescent idiopathic scoliosis. Spine, 28(15 Suppl):S36-43, 2003.

Lowe, T. G.; Alongi, P. R.; Smith, D. A.; O'Brien, M. F.; Mitchell, S. L. \& Pinteric, R. J. Anterior single rod instrumentation for thoracolumbar adolescent idiopathic scoliosis with and without the use of structural interbody support. Spine, 28(19):2232-42, 2003.

Lowe, T.; O'Brien, M.; Smith, D.; Fitzgerald, D.; Vraney, R.; Eule, J. \& Alongi, P. Central and juxta-endplate vertebral body screw placement: a biomechanical analysis in a human cadaveric model. Spine, 27(4):369-73, 2002.

Mohamad, F.; Oka, R.; Mahar, A.; Wedemeyer, M. \& Newton, P. Biomechanical comparison of the screwbone interface: optimization of 1 and 2 screw constructs by varying screw diameter. Spine, 31(16):E535-9, 2006.

Parent, S.; Labelle, H.; Skalli, W.; Latimer, B. \& de Guise, J. Morphometric analysis of anatomic scoliotic specimens. Spine, 27(21):2305-11, 2002.

Scoles, P. V.; Latimer, B. M.; DigIovanni, B. F.; Vargo, E.; Bauza, S. \& Jellema, L. M. Vertebral alterations in Scheuermann's kyphosis. Spine, 16(5):509-15, 1991.

Sucato, D. J. Thoracoscopic anterior instrumentation and fusion for idiopathic scoliosis. J. Am. Acad. Orthop. Surg., 11(4):221-7, 2003.

Sucato, D. J.; Kassab, F. \& Dempsey, M. Analysis of screw placement relative to the aorta and spinal canal following anterior instrumentation for thoracic idiopathic scoliosis. Spine, 29(5):554-9, 2004. 
Sweet, F. A.; Lenke, L. G.; Bridwell, K. H. \& Blanke, K. M. Maintaining lumbar lordosis with anterior single solidrod instrumentation in thoracolumbar and lumbar adolescent idiopathic scoliosis. Spine, 24(16):1655-62, 1999.

Zhang, H.; Sucato, D. J. \& Welch, R. D. Anterior vertebral body screw position placed thoracoscopically: a function of anatomy and surgeon experience in a porcine model. Spine, 29(7):815-22, 2004.

Zhang, H. \& Sucato, D. J. Regional differences in anatomical landmarks for placing anterior instrumentation of the thoracic spine in both normal patients and patients with adolescent idiopathic scoliosis. Spine, 31(2):183-9, 2006.
Correspondence to:

Xiaohe Li

Section of Clinical Anatomy

Department of Anatomy

Southern Medical University

NO.1023 Shatai Southern Road of Baiyun District

Guangzhou

Guangdong Province, P. R.

CHINA

Fax:+86 02061618202

Email:798242742@qq.com

Received: 18-07-2010

Accepted: 22-02-2011 